\title{
The origin of the technical use of "sound argument": a postscript
}

\author{
DAvid HitchCock McMaster University
}

It seems the original perpetrator of the objected-to usage was Irving $M$. Copi, on page 11 of the 1953 First Edition of his much-used Introduction to Logic. (Goldstick 1999: 90)

Even before the 1953 first edition of Copi's text, we find the following entries in the glossary to the 1946 edition of Max Black's Critical Thinking:

Sound argument. An argument whose conclusion is reached by a reliable method. In the case of a deductive argument, an argument having true premises and a valid conclusion. (Black 1946: 387)

Valid. A conclusion (or the argument of which it is a part) is valid when it is impossible for all the premises to be true while the conclusion is false. (Black 1946: 388; italics in original)

Note that what Goldstick rightly calls the "objectionable appropriation" is quite conscious. Black believes, wrongly, that the conclusion of any deductively valid argument with true premisses has been reached from its premisses by a reliable method. Note however that Black, unlike Copi seven years later, allowed that there could be other types of sound arguments: "not all satisfactory, or 'good,' or 'sound' arguments are valid. A sound and fully explicit deductive argument must, however, be valid ..." (Black 1946: 36; italics in original). (By a deductive argument he means one "in which the truth of the premises guarantees (or is intended to guarantee) the truth of the conclusion without appeal to other reasons" (35-36).)

The idea that a deductively valid argument with true premisses is a good argument appears in the textbook literature even earlier than 1946, in Morris R. Cohen and Ernest Nagel's influential and widely used 1934 textbook, $A n$ Introduction to Logic and Scientific Method. Cohen and Nagel, however, use the word 'proof' for such an argument:

It might be of some advantage to use the word 'proof' for the . . . procedure ... by which we conclude a proposition to be true. ... Such a terminology would permit us to say that a proposition is proved when, and only when, a premise implies that proposition and that premise is itself true. (Cohen \& Nagel 1934: 7; italics in original) 
(By 'implies' Cohen and Nagel mean that it is impossible for the premise to be true and the implied proposition false (1934: 8-13).) John Corcoran's introduction to the 1993 re-issue of the logical part of Cohen and Nagel's text implicitly corrects it by defining a "material proof" of a proposition as "a chain of logical reasoning showing the given proposition to be a logical consequence of a set of propositions already known to be true" (Cohen \& Nagel 1993: xviii; italics added).

Cohen and Nagel's 1934 proposal was assimilated in the tradition of formal logic textbooks to that of Black and Copi, as the following passage from a 1969 logic text shows:

If an argument is valid and has only true premisses, it is called sound.

(Some authors prefer to call such arguments "proofs".) (Michalos 1969:

Thus it appears that the originator of the "objectionable appropriation" is Max Black in 1946, and that his mistake was made 12 years earlier in different terminology by Morris Cohen and Ernest Nagel.

\section{References}

Black, Max. (1946). Critical Thinking: An Introduction to Logic and Scientific Method. New York: Prentice-Hall.

Cohen, Morris R., \& Ernest Nagel. (1934), An Introduction to Logic and Scientific Method. New York: Harcourt, Brace.

Cohen, Morris R., \& Ernest Nagel. (1993). An Introduction to Logic, second edition, edited with an introduction by John Corcoran. Indianapolis / Cambridge: Hackett.

Copi, Irving M. (1953). Introduction to Logic. New York: Macmillan.

Goldstick, Dan (1999). "'Soundness' unsound." Informal Logic 19: 90.

Michalos, Alex C. (1969). Principles of Logic. Englewood Cliffs, NJ: Prentice-Hall.

David Hitchcock, Department of Philosophy McMaster University, Hamilton, Ontario, Canada L8S $4 K 1$ hitchckd@sscvax.cis.mcmaster.ca 